\title{
Editorial
}

\section{Perinatal COVID-19 Infection Prevention: Infographics for Patients and Providers}

\author{
Satyan Lakshminrusimha, MD ${ }^{1}$ Aparna Sridhar, MD, MPH ${ }^{2}$ Angel Alberto Herrera Guerra, MD ${ }^{1}$ \\ Rosemary D. Higgins, $\mathrm{MD}^{3}$ George Saade, MD \\ 1 Department of Pediatrics, UC Davis Children's Hospital, Sacramento, \\ California \\ 2 Department of Obstetrics and Gynecology, David Geffen School of \\ Medicine at UCLA, Los Angeles, California \\ ${ }^{3}$ College of Health and Human Sciences, George Mason University, \\ Fairfax, Virginia \\ ${ }^{4}$ Department of Obstetrics and Gynecology, University of Texas \\ Medical Branch, Galveston, Texas
}

Am J Perinatol 2020;37:1185-1188.

Pregnant mothers and their newborns are considered vulnerable population during the COVID-19 (coronavirus disease 2019) pandemic. There are reports of adverse outcomes in pregnant women infected with SARS-CoV-2 (severe acute respiratory syndrome coronavirus 2$)^{1,2}$ even some who were initially asymptomatic only to rapidly deteriorate, requiring intensive care unit admission. ${ }^{3-5}$ SARS-CoV-2 infection in pregnancy has other consequences, even if the mother remains asymptomatic or have mild disease. ${ }^{6,7}$ Pregnant women who test positive for SARS-CoV-2 require isolation and special care during labor, vaginal delivery, or cesarean. ${ }^{8-10}$ Visitors or support persons may not be allowed, and the mother may not be able to visit the nursery if the newborn requires additional care. All the necessary precautions put additional strain on the health care system and workers. Multiple health care workers are needed to safely perform delivery of a woman who tests positive, all of whom would be at risk of infection. ${ }^{11}$

For prevention of infection, the Centers for Disease Control and Prevention (CDC) recommends avoiding close contact, washing the hands often, using a cloth cover over the mouth and nose when around others, covering coughs and sneezes, as well as cleaning and disinfecting frequently touched surfaces daily. Many pregnant women do not seem to be aware of the $\mathrm{CDC}$ recommendations or may not fully realize the consequences of infection. There are anecdotal reports of mothers who continue to participate in gatherings such as baby showers without practicing social distancing or face covering. Family members may also not be diligent in protecting pregnant women living with them.

In contrast, among some pregnant women, news reports of COVID-19 have led to significant anxiety. ${ }^{12}$ Although clinical symptoms of COVID-19 among pregnant women are not different from those of nonpregnant women, lack of appropriate data on the effect of COVID-19 on pregnancy and offspring is a major contributor to the apprehension in this population.

In response to the pandemic, a nationwide registry of pregnant women with suspected or confirmed COVID-19 has been established. This PRIORITY (Pregnancy CoRonavIrus Outcomes RegIsTrY) registry has 882 patients enrolled and 569 COVID-19 patients as of June 21, 2020 (https://priority.ucsf. edu/dashboard). The outcome data from this registry are still pending. A similar registry for pregnant mothers and their newborn has been set by the American Academy of Pediatrics (AAP)-Section on Neonatal Perinatal Medicine. This database (https://collaborate.aap.org/SONPM/Pages?National-Perinatal-COVID19-Registry.aspx) has reported 1,106 mother-infant dyads with 33 positive infants with short-term outcomes as of June 21,2020 . These databases and published reports demonstrate that compared with elderly population, the morbidity and mortality are low among obstetric ${ }^{6}$ and neonatal patients. ${ }^{13-15}$ However, long-term outcomes of perinatal COVID-19 are not known. In addition, perinatal COVID-19 imposes a significant burden on the patients and their families, as well as the healthcare system. As the pandemic spreads across the United States, majority of the obstetric units have started screening and testing of all patients admitted for childbirth. The results of the universal testing helped hospitals determine isolation practices, use of personal protective equipment by healthcare workers, and allocation of other resources. The universal screening and testing of asymptomatic patients also opened opportunities to understand
Address for correspondence Aparna Sridhar, MD, MPH, Department of Obstetrics and Gynecology, David Geffen School of Medicine at UCLA, 1010 Veteran Ave, Los Angeles, CA 90095

(e-mail: asridhar@mednet.ucla.edu).
Copyright (c 2020 by Thieme Medical Publishers, Inc., 333 Seventh Avenue, New York, NY 10001, USA. Tel: +1(212) 760-0888.
DOI https://doi.org/ 10.1055/s-0040-1714387. ISSN 0735-1631. 


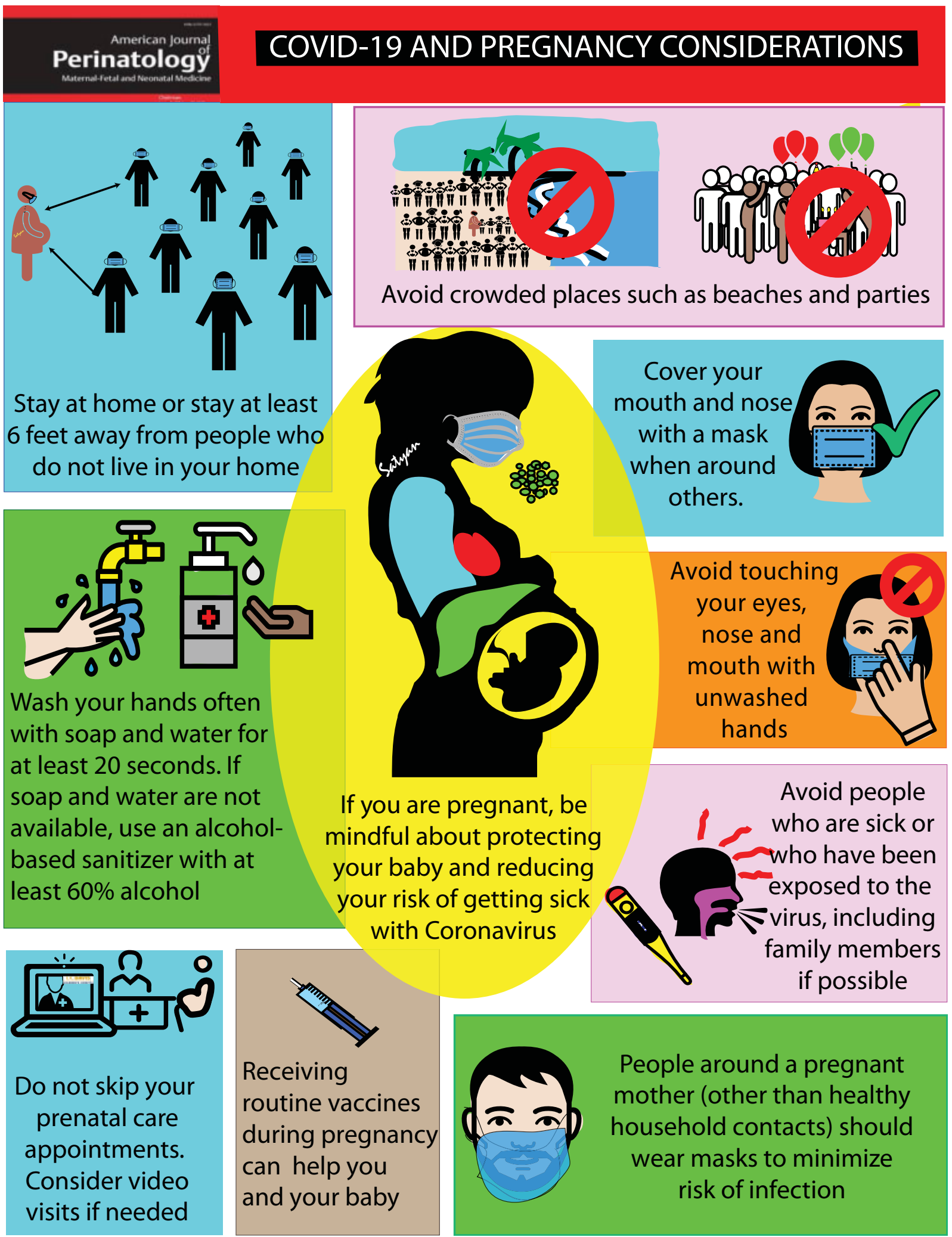

Fig. 1 COVID-19 and pregnancy considerations: general guidelines for use of masks, physical distancing and avoiding crowds, hand hygiene, and antepartum care are shown. COVID-19, coronavirus disease 2019.

Copyright $\odot$ Satyan Lakshminrusimha. Readers are welcome to use this infographic as poster, slide, or brochure for patient, parent, and trainee education.

community prevalence of infection. ${ }^{16}$ From April to early June 2020, multiple studies have published on the prevalence of asymptomatic infection among pregnant women admitted to labor and delivery, ranging from $1.5^{17}$ to $15 \% .{ }^{18}$
The CDC has proposed a set of generic guidelines to ensure the safety of pregnant mothers during the pandemic. These include general precautions such as physical distancing, hand washing, cleaning, and disinfection of the surrounding areas. 

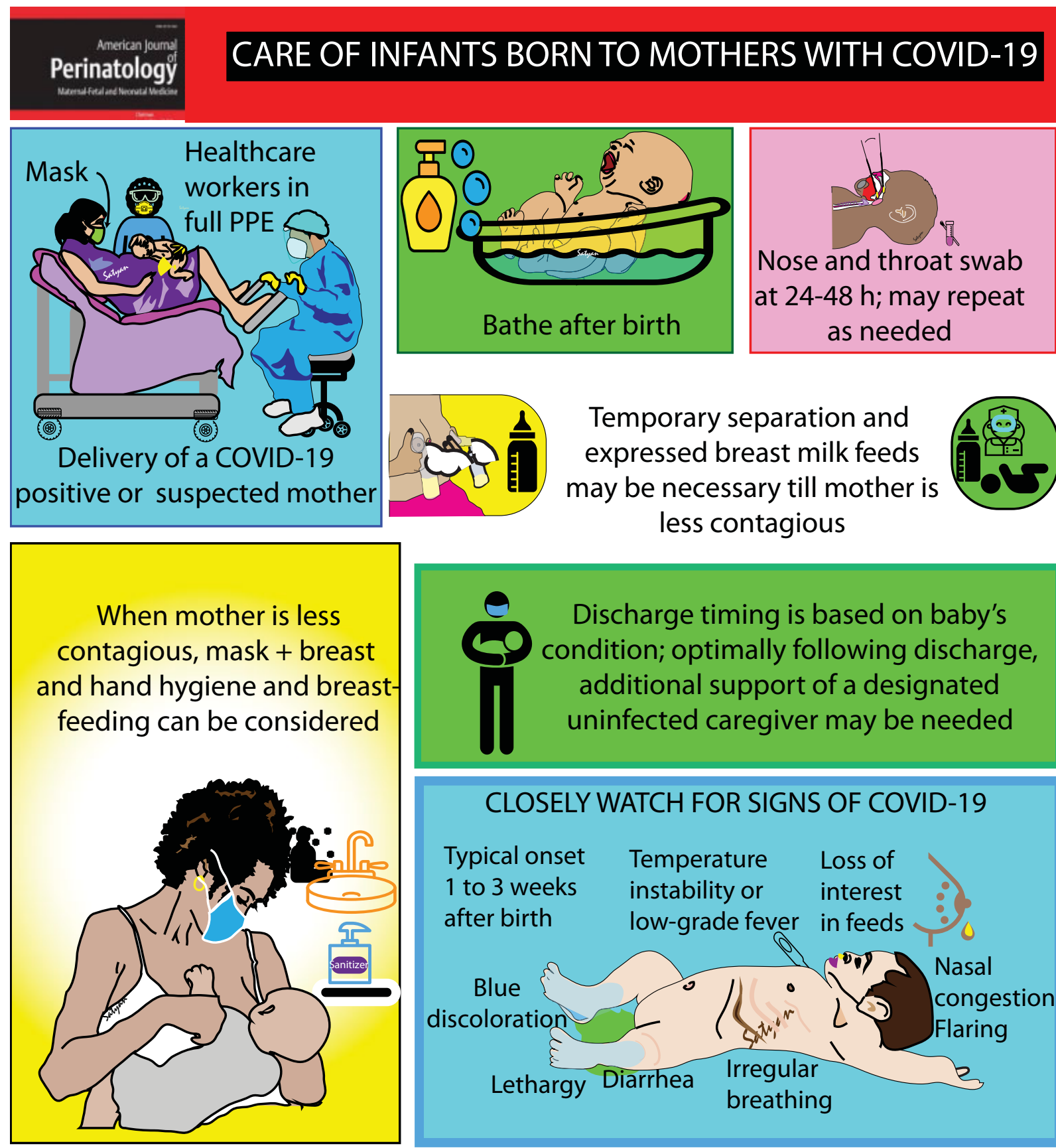
Temporary separation and expressed breast milk feeds may be necessary till mother is less contagious
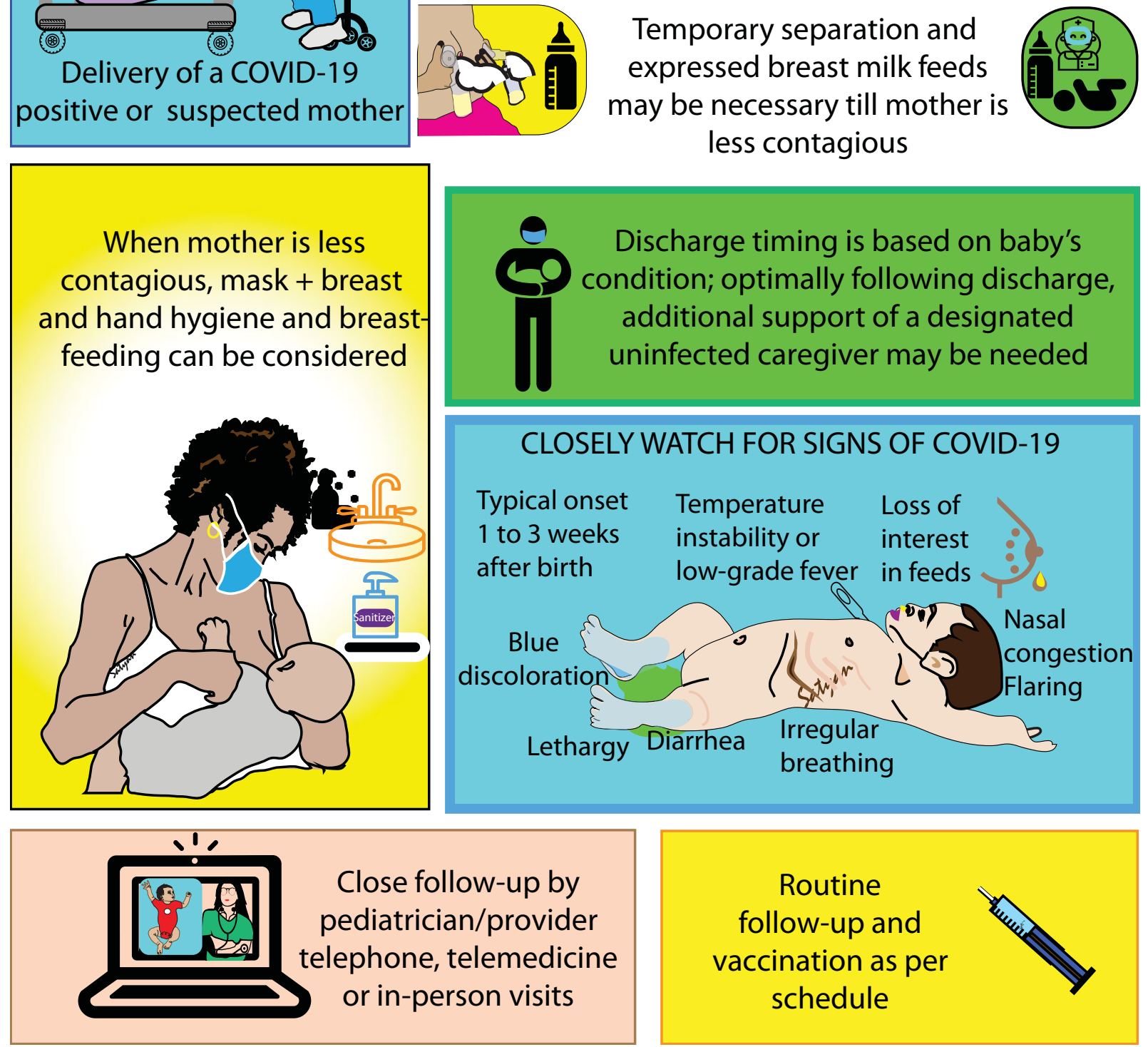

Fig. 2 Care of infants born to mothers with COVID-19: care during birth and soon after delivery, possible need for temporary separation, breastfeeding, warning signs of neonatal COVID-19, and recommendations for follow-up are shown. COVID-19, coronavirus disease 2019. Copyright $\odot$ Satyan Lakshminrusimha. Readers are welcome to use this infographic as poster, slide, or brochure for patient, parent, and trainee education.

Specifically, the CDC encourages pregnant women to continue standard prenatal care and immunization procedures. Major professional organizations such as the American College of Obstetricians and Gynecologists (ACOG), Society of Maternal-
Fetal Medicine (SMFM), and AAP have published pregnancyand breastfeeding-specific information page to help patients. The ACOG and CDC recommend face coverings for pregnant women, especially in places where physical distancing is 
harder to practice. Cloth masks are reasonable options for most pregnant women. Cloth masks are likely effective in preventing transmission from large droplets and keep the rates of community transmission down. ${ }^{19}$ The ACOG and SMFM propose telehealth appointments to replace some in-person visits to adapt to the social distancing guidelines.

Guidelines from major governmental and professional organizations are in text form and difficult for patients and parents to understand and follow. Use of simple infographics is likely to enhance medical information for public consumption. ${ }^{20}$ We have summarized these guidelines in the form of two infographics (for pregnancy and care of newborn) in -Figs. 1 and 2. Spanish versions are also included in - Supplementary Figs. S1 and S2 (available in the online version). We have also included these infographics in highresolution files on the journal's website. We anticipate that these infographics will be useful for display in clinician's offices, delivery rooms, and/or nursery, and for creating informative brochures for patients/parents. We recommend that health care providers educate their patients about approaches to prevent infection with SARS-CoV-2 at the first prenatal visit and check at each visit whether the patient is following the recommendations. We need to better control the rates of infection in pregnant women before the anticipated second wave. Otherwise, the health care system in the prenatal clinics as well as the delivery and neonatal services are likely to be overwhelmed.

\section{Conflict of Interest}

None declared.

\section{References}

1 Galang RR, Chang K, Strid P, et al. Severe coronavirus infections in pregnancy: a systematic review. Obstet Gynecol 2020 (e-pub ahead of print). Doi: 10.1097/AOG.0000000000004011

2 Sentilhes L, De Marcillac F, Jouffrieau C, et al. COVID-19 in pregnancy was associated with maternal morbidity and preterm birth. Am J Obstet Gynecol 2020 (e-pub ahead of print). Doi: 10.1016/j.ajog.2020.06.022

3 Breslin N, Baptiste C, Miller R, et al. Coronavirus disease 2019 in pregnancy: early lessons. Am J Obstet Gynecol MFM 2020;2(02): 100111

4 Lucarelli E, Behn C, Lashley S, Smok D, Benito C, Oyelese Y. Mechanical ventilation in pregnancy due to COVID-19: a cohort of three cases. Am J Perinatol 2020 (e-pub ahead of print). Doi: $10.1055 / \mathrm{s}-0040-1713664$
5 Silverstein JS, Limaye MA, Brubaker SG, et al. Acute respiratory decompensation requiring intubation in pregnant women with SARS-CoV-2 (COVID-19). AJP Rep 2020;10(02):e169-e175

6 Smith V, Seo D, Warty R, et al. Maternal and neonatal outcomes associated with COVID-19 infection: a systematic review. PLoS One 2020;15(06):e0234187

7 London V, McLaren R Jr, Atallah F, et al. The relationship between status at presentation and outcomes among pregnant women with COVID-19. Am J Perinatol 2020 (e-pub ahead of print). Doi: 10.1055/s-0040-1712164

8 Dotters-Katz SK, Hughes BL. Considerations for obstetric care during the COVID-19 pandemic. Am J Perinatol 2020;37(08):773-779

9 Peña JA, Bianco AT, Simpson LL, et al. A survey of labor and delivery practices in New York City during the COVID-19 pandemic. Am J Perinatol 2020 (e-pub ahead of print). Doi: 10.1055/s-0040-1713120

10 Rasmussen SA, Jamieson DJ. Caring for women who are planning a pregnancy, pregnant, or postpartum during the COVID-19 pandemic. JAMA 2020 (e-pub ahead of print). Doi: 10.1001/jama.2020.8883

11 Chandrasekharan P, Vento M, Trevisanuto D, et al. Neonatal resuscitation and postresuscitation care of infants born to mothers with suspected or confirmed SARS-CoV-2 infection. Am J Perinatol 2020;37(08):813-824

12 Berthelot N, Lemieux R, Garon-Bissonnette J, Drouin-Maziade C, Martel É, Maziade M. Uptrend in distress and psychiatric symptomatology in pregnant women during the coronavirus disease 2019 pandemic. Acta Obstet Gynecol Scand 2020;99(07):848-855

13 Alzamora MC, Paredes T, Caceres D, Webb CM, Valdez LM, La Rosa M. Severe COVID-19 during pregnancy and possible vertical transmission. Am J Perinatol 2020;37(08):861-865

14 Blumberg DA, Underwood MA, Hedriana HL, Lakshminrusimha S. Vertical transmission of SARS-CoV-2: what is the optimal definition? Am J Perinatol 2020;37(08):769-772

15 Buonsenso D, Costa S, Sanguinetti M, et al. Neonatal late onset infection with severe acute respiratory syndrome coronavirus 2. Am J Perinatol 2020;37(08):869-872

16 Sutton D, Fuchs K, D'Alton M, Goffman D. Universal screening for SARS-CoV-2 in women admitted for delivery. N Engl J Med 2020; 382(22):2163-2164

17 Goldfarb IT, Diouf K, Barth WH, et al. Universal SARS-CoV-2 testing on admission to the labor and delivery unit: low prevalence among asymptomatic obstetric patients. Infect Control Hosp Epidemiol 2020 (e-pub ahead of print). Doi: 10.1056/NEJMc2009316

18 Bianco A, Buckley AB, Overbey J, et al. Testing of patients and support persons for coronavirus disease 2019 (COVID-19) infection before scheduled deliveries. Obstet Gynecol 2020 (e-pub ahead of print). Doi: 10.1097/AOG.0000000000003985

19 Esposito S, Principi N, Leung CC, Migliori GB. Universal use of face masks for success against COVID-19: evidence and implications for prevention policies. Eur Respir J 2020;55(06):2001260

20 Royal KD, Erdmann KM. Evaluating the readability levels of medical infographic materials for public consumption. J Vis Commun Med 2018;41(03):99-102 